\title{
ARBORIZAÇÃO VIÁRIA NA CIDADE DE TAUBATÉ, SP: NO CENTRO COMERCIAL HISTÓRICO E UM BAIRRO RESIDENCIAL MODERNO
}

\author{
Eder Salim Minhoto ${ }^{1}$, Evoni Antunes Monteiro ${ }^{1}$, Simey Thury Vieira Fisch ${ }^{1,2}$
}

(recebido em 22.01.2009 e aceito para publicação em 18.06.2009)

\begin{abstract}
RESUMO
O objetivo principal deste estudo foi avaliar características quanto ao porte, qualidade, plantio e poda das árvores de duas regiões no município de Taubaté-SP, o centro e um bairro residencial. Foram percorridos $11,785 \mathrm{~km}$ de calçadas e 0,385 km de canteiros centrais, encontrando-se 415 indivíduos pertencentes a 50 espécies, sendo que $40 \%$ dessas representadas por apenas um espécime. As espécies sibipiruna (Caesalpinia peltophoroides Benth.), areca-bambu (Dypsis lutescens H. Wend), ipê-roxo (Tabebuia avellanedae L.) e ficus (Ficus benjamina L.) representaram 52\% das espécies levantadas. Em relação ao porte das árvores plantadas na região central, 47,22\% foram caracterizadas como espécies inadequadas ao local, principalmente pela presença de fiação elétrica e estreitamento de ruas e calçadas, típicas de centros históricos. Já no bairro analisado, 47,61\% das espécies levantadas foram consideradas adequadas por se tratar de uma área recente de ruas largas com canteiros centrais. Devido, principalmente, ao conflito com a fiação elétrica, nas duas regiões analisadas podas são realizadas quase sempre sem critérios técnicos, comprometendo arquitetura da copa e a saúde dos espécimes plantados.
\end{abstract}

Palavras-chave: Arborização urbana, podas e inventário quali-quantitativo, espécies arbóreas.

\footnotetext{
1 Programa de Pós-Graduação em Ciências Ambientais- PPG-CA.

2 UNITAU-Universidade de Taubaté, Instituto Básico de Biociências - Campus do Bom Conselho Praça Marcelino Monteiro, 63. CEP: 12030-010, Taubaté, SP- Brasil, simey@unitau.br
} 


\title{
STREET ARBORIZATION IN THE CITY OF TAUBATÉ, SP: IN THE HISTORICAL COMMERCIAL DOWNTOWN AND A MODERN RESIDENTIAL QUARTER
}

\begin{abstract}
The main objective of this study was to analyze and to evaluate characteristics related to the height, quality, plantation and pruning of the trees of two areas (center and residential quarters) in Taubaté-SP. 11,785 km of sidewalk and 0,385 km of central seedbeds were covered, meeting 415 individuals belonging to 50 species, considering that $40 \%$ of these were represented by only one specie. The species sibipiruna (Caesalpinia peltophoroides Benth.), areca-bamboo palm (Dypsis lutescens $\mathrm{H}$. Wend), ipê-roxo (Tabebuia avellanedae L.) and ficus (Ficus benjamina L.) represented $52 \%$ of the sampled species. Considering the height of the trees planted in the central region, $47.22 \%$ were characterized as inappropriate species for the place, mainly because of the presence of electric wiring and the narrows of the streets and sidewalks, typical of historical centers. In the residential quarter analyzed, $47.61 \%$ of the sampled species were considered appropriated because it is a new area with wide streets and central seedbeds. Mainly due to the fact that there is a conflict with the electric wiring in the two analyzed regions pruning is done without technical criteria, depriving its characteristics and compromising planted species.
\end{abstract}

Key-words: Urban arborization, pruning and quali-quantitative inventory, arboreal species. 


\section{INTRODUÇÃO}

Atualmente sabe-se que muitas são as vantagens que podem ser alcançadas com a arborização de vias públicas. Dentre os vários aspectos positivos da arborização, destacamse: a mitigação da poluição sonora, filtro ambiental, equilíbrio da temperatura ambiente, atração para a avifauna e a harmonia paisagística e ambiental do espaço urbano (SÃO PAULO, 2006). A arborização urbana torna-se uma opção para a obtenção de benefícios diretos e indiretos relacionados à qualidade ambiental urbana, desde que executada de forma planejada. Logo, um conhecimento da situação da arborização é essencial para seu adequado manejo e planejamento.

$\mathrm{Na}$ arborização de cidades brasileiras observa-se uma crescente substituição da flora nativa por plantas exóticas e o plantio de espécies inadequadas, sem critérios técnicos ou paisagísticos e em lugares impróprios (TOLEDO FILHO e PARENTE, 1988; GOYA, 1994; YAMAMOTO et al., 2004).

O conhecimento das características de uma espécie arbórea, tal como sua arquitetura, é de extrema importância para que o plantio atinja os objetivos esperados (LORENZI, 1998; SEITZ, 1990; SILVA FILHO e BORTOLETO, 2005; ANGELIS NETO et al., 2006). Observase, também, que as implantações dos sistemas elétricos de distribuição e a arborização das cidades são em geral realizadas de modo independentes. O resultado disso é que árvores de médio e grande porte, e as redes elétricas passam a disputar o mesmo espaço físico (PALERMO JUNIOR, 1985). Esse é o motivo da maioria das interrupções de energia elétrica nas redes de distribuição, segundo a empresa de eletricidade de Eletricidade de São Paulo (Eletropaulo, 2008).

A cidade de Taubaté, localizada na região do Vale do Paraíba, no Estado de São Paulo, foi fundada em 1640, e a exemplo de cidades outras antigas, possui em seu primitivo sítio urbano, onde hoje se localiza a região central, ruas e calçadas estreitas. Atualmente o município apresenta, também, bairros mais modernos e planejados, com calçadas e ruas largas providas de canteiros centrais separando as vias em duas mãos. Mas, por ser uma cidade com desenvolvimento muito rápido, necessita de um planejamento adequado para garantir a qualidade de vida de seus habitantes.

Visando fornecer subsídios ao planejamento que valorizem o aspecto paisagístico e ecológico, com a utilização de espécies nativas e o plantio de árvores adequadas e compatíveis com as características físicas da cidade, os objetivos do presente trabalho foram avaliar e analisar algumas características da arborização viária de duas regiões da cidade de Taubaté, a mais antiga (região central) e outra mais moderna e planejada (Jardim das Nações), e identificar conflitos entre a arborização existente e a rede de distribuição de energia elétrica. 
Arborização viável na cidade de Taubaté...

\section{MATERIAL E MÉTODOS}

\section{Área de estudo}

Dentro da área urbana do município de Taubaté-SP foram inventariadas duas regiões: (a) a região mais antiga, correspondente ao núcleo primevo do povoado de São Francisco das Chagas de Taubaté e atualmente pertencente a uma parte do centro comercial. Dessa região foram percorridas quatorze ruas, formando doze quarteirões, resultando em uma área aproximadamente igual a $130.000 \mathrm{~m}^{2}$; (b) a mais moderna, correspondente ao bairro Jardim das Nações, região estritamente residencial, de alto padrão sócio-econômico com grandes áreas de espaços livres ocupados por jardins e árvores. Foram percorridas sete ruas e trechos de duas avenidas, formando oito quarteirões, resultando em uma área aproximadamente igual a $122.000 \mathrm{~m}^{2}$.

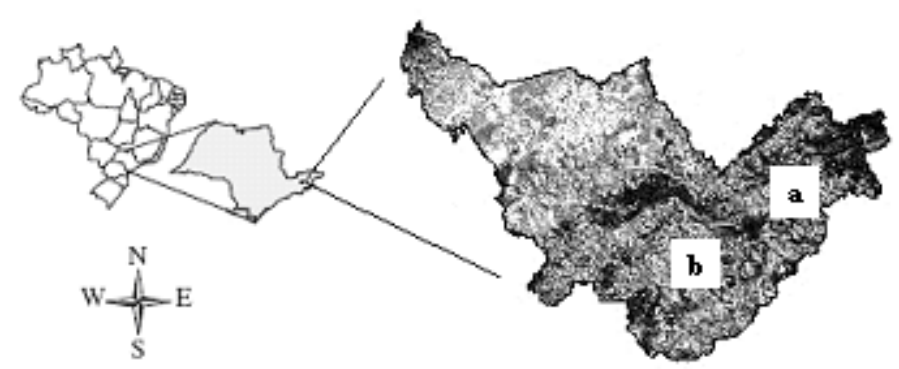

a

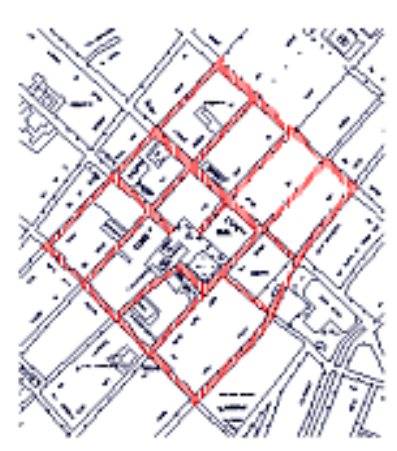

b

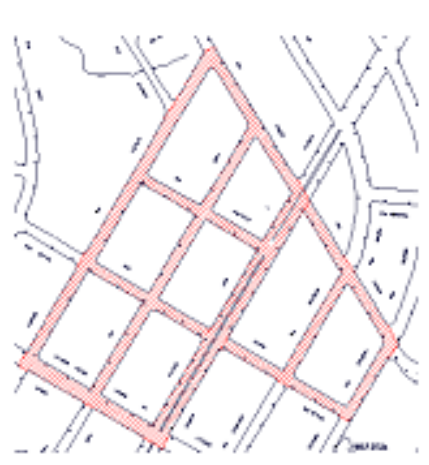

Figura 1: Localização do Município de Taubaté e das regiões (a) Centro e (b) bairro Jardim das Nações, com respectivas áreas percorridas.

\section{Levantamento da arborização}

Por meio da planta da cidade de Taubaté foi possível realizar o levantamento da arborização. As espécies foram identificadas com base em literaturas especializadas (SANCHOTENE, 1985; LORENZI, 1998; LORENZI et al., 2003).

A variável principal utilizada foi o número de árvores por quilômetro linear de calçada, por ser de manuseio mais simples, como recomendado por Rachid (1999). Essa variável foi 
definida como a razão entre o número total de árvores existentes e o total de quilômetros de calçada na área de estudo.

De cada rua inventariada foram registrados o total de árvores existentes e suas características, como: o local de plantio, o comprimento e a largura das ruas e a largura das calçadas. Quando a rua ou a calçada possuía diferentes larguras, três medidas eram tomadas e o valor final correspondia à média aritmética dessas medidas.

A fim de se compilar os dados em planilhas de forma prática e de acordo com as necessidades deste trabalho, criou-se adaptações dos trabalhos de Lima (1993) e Silva Filho et al. (2002), onde se designou códigos em numeração arábica. As variáveis levantadas foram assim definidas:

-Sistema viário (rua, bairro, quarteirão, comprimento e largura total da via, tipo-comercial ou residencial, largura das calçadas);

-Espécie (número do quarteirão ao qual a árvore pertence, numeração crescente de cada árvore encontrada e espécie à qual pertence o indivíduo analisado);

-Plantio (área de plantio livre, porte da espécie em relação ao espaço disponível, levando-se em consideração o porte natural da espécie na fase adulta, fiação; se muda ou não);

-Porte da árvore medida em relação aos condutores da rede elétrica aérea secundária (6,5 m) e primária (8,85 m); PAP (perímetro da árvore à altura do peito);

-Qualidade (bifurcação a 2,10 m de altura, considerando a possibilidade de passagem livre de veículos e pedestres, condição arquitetônica da copa e superficialidade do sistema radicular);

-Poda (avaliação geral da poda praticada: se a árvore não recebeu poda de condução, atrapalhando a passagem de veículos e/ou pedestres; se estava malfeita, deixando tocos e lascas; se adequada).

\section{RESULTADOS E DISCUSSÃO}

\section{Caracterização das vias públicas}

$\mathrm{Na}$ comparação dos dados, entre a região central e o bairro, notou-se que, para o centro os valores médios para as larguras das ruas e calçadas, respectivamente, 6,75 e 1,78 m, identificam um leito carroçável e passeios estreitos. Esses valores são justificados pelo fato dessa área ser a mais antiga da cidade. Ao contrário, o bairro Jardim das Nações, por ser uma área residencial planejada, apresentou valores médios maiores, sendo 8,70 m para as larguras de vias e 2,80 m para as larguras de calçadas.

Valores próximos aos encontrados na região central de Taubaté, também foram verificados por Lima (1993) na cidade de Piracicaba-SP que, fundada em 1767, é também uma cidade antiga, onde a largura média das ruas e calçadas são, respectivamente, 6,3 e 2,0 m. Esses resultados podem também ser comparados pelos obtidos por Rachid (1999) 


\section{Arborização viável na cidade de Taubaté...}

em seu estudo do sistema viário da cidade de São Carlos-SP, onde encontrou uma largura média, para as ruas, de $8,24 \mathrm{~m}$ e, para as calçadas, de 2,29 $\mathrm{m}$, valores maiores que os encontrados nas cidades acima mencionadas. Esta cidade foi fundada em 1865, o que a torna menos antiga que Taubaté e Piracicaba.

A região central de Taubaté, predominantemente ocupada pelo comércio, é a região mais problemática quanto à arborização, devido a diversos fatores como: calçadas e ruas estreitas, trânsito intenso de pessoas e veículos, edificações sem recuo e o interesse dos comerciantes em não ter nada obstruindo a fachada de seus estabelecimentos. Portanto, as condições verificadas na área central tornam-na extremamente restrita a implantação de uma arborização convencional. Já no bairro Jardim das Nações as calçadas são largas, as avenidas possuem canteiros-centrais e não há problemas quanto ao afastamento predial. Portanto, assim como em muitas cidades com centros históricos, Taubaté possui regiões urbanas com realidades diferentes que devem ser avaliadas com critério quando do planejamento da arborização. Dessa forma, segundo as recomendações de alguns autores (PEDROSA, 1983; PALERMO JUNIOR, 1985; CODI, 1990; RIBEIRO et al., 1992; ELETROPAULO METROPOLITANA, s.d.), para a escolha das espécies (quanto ao porte e sistema radicular) adequadas é necessário relacionar a largura das calçadas e das vias e o espaçamento mínimo entre espécimes.

\section{Caracterização das espécies}

Nos $12,17 \mathrm{~km}$ de calçadas laterais e canteiros centrais, sendo $6,095 \mathrm{~km}$ no centro e 6,075 km no Jardim das Nações, foram encontrados 415 exemplares vegetais englobando árvores e arbustos. Em relação ao número de árvores observadas por quilômetro de calçada e canteiro central, obteve-se um valor igual a 11,81 árvores $/ \mathrm{km}$ no centro e 56,46 árvores/km no Jardim das Nações, o que mostra uma arborização bem mais presente no bairro, justificada pelo próprio tipo de ocupação de cada região.

$\mathrm{Na}$ Tabela 1 encontram-se relacionadas todas as espécies levantadas, a quantidade e a percentagem em relação ao total. Na área central, foram encontrados 72 exemplares, e no bairro, 343. Foram registradas 50 espécies diferentes, sendo 21 destas espécies representadas por apenas um indivíduo. Isso representa $40 \%$ do total, o que demonstra que boa parte do plantio de árvores nas calçadas tem sido feita pela própria população.

A espécie mais freqüente na área central foi a Caesalpinia peltophoroides Benth. (sibipiruna), representa quase $35 \%$ do total das árvores plantadas. No bairro Jardim das Nações, a espécie mais encontrada foi a Dypsis lutescens $\mathrm{H}$. Wendl. (areca-bambu), com pouco mais de $22 \%$ do total de espécies da área. No somatório do número de árvores registradas nas duas áreas, a areca-bambu foi a que apresentou a maior ocorrência, com 18,31\% do total geral (76 indivíduos). 
Estas duas espécies, mais a Tabebuia avellanedae Lorentz (ipê-roxo), com 8,43\%, e a Ficus benjamina L. (ficus), com 9,88\%, representam pouco mais de $52 \%$ de todas as espécies plantadas nas duas regiões pesquisadas. Portanto, embora tenha sido encontrado um número relativamente alto de diferentes espécies, apenas quatro delas perfizeram mais da metade dos indivíduos encontrados na área de estudo. Isso determina uma arborização viária pouco diversificada, o que a caracteriza como homogênea e pode vir a ser um aspecto negativo, favorecendo o ataque de pragas e doenças.

Essa homogeneidade da arborização é comum em muitas cidades brasileiras, conforme verificado em Curitiba - PR (MILANO, 1984), em Piracicaba - SP (LIMA, 1993), em São Carlos - SP (RACHID, 1999), em Volta Redonda - RJ (CRISPIM, 2000), na Estância de São Pedro - SP (BORTOLETO et al., 2006) e em Belo Horizonte - MG (SILVA et al., 2006). Nestas cidades também ficou constatada a grande freqüência da sibipiruna, sendo sempre uma das espécies mais plantadas.

Segundo Oliveira Junior (1996), um programa da Secretaria da Agricultura do Estado de São Paulo, no início da década de 1960, com o objetivo principal de amenizar as temperaturas no interior paulista, incentivou a arborização urbana promovendo o plantio de espécies de grande porte, de rápido crescimento e boa adaptação às condições biofísicas. Estas condições foram decisivas para a adoção das sibipirunas, resultando em uma alta freqüência dessa espécie em várias cidades do Estado. Atualmente estas árvores têm se mostrado como um incômodo à população em função de seus folíolulos muito pequenos e caducifóilos, que entopem calhas, penetram em frestas e são difíceis de serem varridos.

Destaca-se ainda o emprego na arborização de Taubaté de espécies que chegam a representar quase metade dos indivíduos levantados e que não são árvores propriamente ditas, como palmeiras (palmeira-cariota, areca-bambu, palmeira-leque, palmeira-fênix, palmeira-imperial, jerivá) e arbustos (tuia, murta, hibisco, espirradeira, flamboyant-mirim, campainha, cróton, dracena e guaraná). Portanto, não podem ser desprezadas quando do levantamento quantitativo da arborização urbana. Algumas são de uso consagrado e inclusive são recomendadas por concessionárias de energia elétrica como "árvores de pequeno porte". Em muitos casos são empregadas visando algum embelezamento paisagístico e não sendo levados em conta outros problemas por elas gerados (trânsito de pedestres, iluminação pública, tamanho das folhas das palmeiras etc.) 
Arborização viável na cidade de Taubaté...

TABELA 1: Espécies empregadas na arborização nas áreas levantadas da cidade de Taubaté-SP.

\begin{tabular}{|c|c|c|c|c|c|c|c|c|}
\hline \multirow{2}{*}{ Nome científico } & \multirow{2}{*}{ Família } & \multirow{2}{*}{ Nome vulgar } & \multicolumn{3}{|c|}{ Quantidade de indivíduos } & \multicolumn{3}{|c|}{ Freqüência percentual } \\
\hline & & & Centro & Jd. Nações & Total & Centro & Jd. Nações & Total \\
\hline Acacia podaliriaefolia & Mimosaceae & acácia-mimosa & - & 3 & 3 & - & 0,87 & 0,72 \\
\hline Acer platanoides & Aceraceae & plátanos & - & 1 & 1 & - & 0,29 & 0,24 \\
\hline Araucaria angustifolia & Araucariaceae & araucária & - & 1 & 1 & - & 0,29 & 0,24 \\
\hline Bauhinia variegata & Caesalpiniaceae & pata-de-vaca & 1 & 10 & 11 & 1,39 & 2,92 & 2,65 \\
\hline $\begin{array}{l}\text { Brugmansia } \\
\text { suaveolens }\end{array}$ & Solanaceae & campainha & - & 4 & 4 & - & 1,17 & 0,96 \\
\hline Caesalpinia echinata & Caesalpiniaceae & pau-brasil & - & 1 & 1 & - & 0,29 & 0,24 \\
\hline $\begin{array}{l}\text { Caesalpinia } \\
\text { peltophoroides }\end{array}$ & Caesalpiniaceae & sibipiruna & 25 & 39 & 64 & 34,72 & 11,37 & 15,42 \\
\hline $\begin{array}{l}\text { Caesalpinia } \\
\text { pulcherrima }\end{array}$ & Caesalpiniaceae & flamboyant-mirim & - & 1 & 1 & - & 0,29 & 0,24 \\
\hline Cariniana estrellensis & Lecythidaceae & jequitibá & - & 2 & 2 & - & 0,58 & 0,48 \\
\hline Cariota urens & Arecaceae & palmeira-cariota & - & 4 & 4 & - & 1,17 & 0,96 \\
\hline Cassia fistula & Caesalpiniaceae & cácia - imperial & - & 2 & 2 & - & 0,58 & 0,48 \\
\hline Dypsis lutescens & Arecaceae & areca-bambu & - & 76 & 76 & - & 22,16 & 18,31 \\
\hline Codiaeum variegatum & Euphorbiaceae & cróton & 1 & 4 & 5 & 1,39 & 1,17 & 1,20 \\
\hline Coffea arabica & Rubiaceae & cafeeiro & - & 1 & 1 & - & 0,29 & 0,24 \\
\hline Delonix regia & Caesalpiniaceae & flamboyant & - & 2 & 2 & - & 0,58 & 0,48 \\
\hline Dracena sp. & Liliaceae & dracena & - & 1 & 1 & - & 0,29 & 0,24 \\
\hline Enterolobium timbouva & Fabaceae & tamboril & - & 10 & 10 & - & 2,92 & 2,41 \\
\hline Eriobotrya japonica & Rosaceae & nêspera & - & 2 & 2 & - & 0,58 & 0,48 \\
\hline Eugenia jambolana & Myrtaceae & jambolão & - & 1 & 1 & - & 0,29 & 0,24 \\
\hline Eugenia sp. & Myrtaceae & jambo & - & 1 & 1 & - & 0,29 & 0,24 \\
\hline Ficus benjamina & Moraceae & ficus & 9 & 32 & 41 & 12,5 & 9,33 & 9,88 \\
\hline Grevillea robusta & Proteaceae & grevilha-robusta & 2 & - & 2 & 2,78 & - & 0,48 \\
\hline Hibiscus rosa-sinensis & Malvaceae & hibisco & 6 & 5 & 11 & 8,34 & 1,46 & 2,65 \\
\hline $\begin{array}{l}\text { Jacaranda } \\
\text { mimosaefolia }\end{array}$ & Bignoniaceae & $\begin{array}{l}\text { jacarandá- } \\
\text { mimoso }\end{array}$ & - & 1 & 1 & - & 0,29 & 0,24 \\
\hline Lafoensia glyptocarpa & Lithraceae & mirindiba & - & 1 & 1 & - & 0,29 & 0,24 \\
\hline Lagerstroemia indica & Lythraceae & resedá & 8 & 4 & 12 & 11,11 & 1,17 & 2,89 \\
\hline Licania tomentosa & Chrysabalanaceae & oiti & - & 1 & 1 & - & 0,29 & 0,24 \\
\hline Ligustrum lucidum & Oleaceae & alfeneiro & 6 & 8 & 14 & 8,33 & 2,33 & 3,37 \\
\hline Ligustrum sp. & Oleaceae & ligustro & - & 1 & 1 & - & 0,29 & 0,24 \\
\hline Livistona sp. & Arecaceae & palmeira-leque & - & 2 & 2 & - & 0,58 & 0,48 \\
\hline Mangifera indica & Anacardiaceae & mangueira & - & 1 & 1 & - & 0,29 & 0,24 \\
\hline Michelia champaca & Magnoliaceae & magnólia & - & 15 & 15 & - & 4,37 & 3,61 \\
\hline Murraya exotica & Myrtaceae & murta & 6 & 8 & 14 & 8,33 & 2,33 & 3,37 \\
\hline Nerium oleander & Apocynaceae & espirradeira & 1 & 3 & 4 & 1,39 & 0,87 & 0,96 \\
\hline Paulinia sp. & Sapindaceae & guaraná & - & 1 & 1 & - & 0,29 & 0,24 \\
\hline Persea americana & Lauraceae & abacateiro & - & 2 & 2 & - & 0,58 & 0,48 \\
\hline Phoenix roebelenii & Arecaceae & palmeira-fênix & - & 1 & 1 & - & 0,29 & 0,24 \\
\hline Psidium guajava & Myrtaceae & goiabeira & - & 1 & 1 & - & 0,29 & 0,24 \\
\hline Rollinia mucosa & Annonaceae & fruta-do-conde & - & 1 & 1 & - & 0,29 & 0,24 \\
\hline Roystonea oleracea & Arecaceae & palmeira-imperial & - & 5 & 5 & - & 1,46 & 1,20 \\
\hline
\end{tabular}




\begin{tabular}{|c|c|c|c|c|c|c|c|c|}
\hline Schinus molle & Anacardiaceae & aroeira-salsa & - & 1 & 1 & - & 0,29 & 0,24 \\
\hline Stenolobium stans & Bignoniaceae & ipê-de-jardim & 1 & 4 & 5 & 1,39 & 1,17 & 1,20 \\
\hline Syagrus romanzoffiana & Arecaceae & palmeira-jerivá & 5 & - & 5 & 6,94 & - & 1,20 \\
\hline Tabebuia avellanedae & Bignoniaceae & ipê-roxo & 1 & 34 & 35 & 1,39 & 9,91 & 8,43 \\
\hline Tabebuia chrysotricha & Bignoniaceae & ipê-amarelo & - & 8 & 8 & - & 2,33 & 1,93 \\
\hline Tabebuia heptaphylla & Bignoniaceae & ipê-rosa & - & 1 & 1 & - & 0,29 & 0,24 \\
\hline Tabebuia roseo-alba & Bignoniaceae & ipê-branco & - & 1 & 1 & - & 0,29 & 0,24 \\
\hline Terminalia catappa & Combretaceae & chapéu-de-sol & - & 12 & 12 & - & 3,50 & 2,89 \\
\hline Thuya compacta & Cupressaceae & tuia & - & 16 & 16 & - & 4,66 & 3,86 \\
\hline Tibouchina granulosa & Melastomataceae & quaresmeira & - & 7 & 7 & - & 2,04 & 1,69 \\
\hline TOTAL & & & 72 & 343 & 415 & 100 & 100 & 100 \\
\hline
\end{tabular}

\section{Análise do porte das árvores}

Do total de plantas, $57,83 \%$ não foram registradas quanto ao de PAP pelo fato de não terem atingido 1,30 m de altura na época de medição, ou por apresentarem caules múltiplos, como o caso da palmeira areca-bambu. A porcentagem de mudas em relação ao total de indivíduos correspondeu a 28,19\% (117 indivíduos), sendo que grande parte dessas mudas $(23,07 \%)$ era de areca-bambu, todas plantadas no bairro Jardim das Nações.

$\mathrm{Na}$ análise dos registros de PAP dos exemplares de sibipiruna observou-se que pela média apresentada $(1,28 \mathrm{~m})$ era de se esperar que quase a totalidade destas estivesse a uma altura superior de $8,0 \mathrm{~m}$, porém grande parte $(43,75 \%)$ estava sob a fiação, o que ocasionou uma alta incidência de podas drásticas por parte da concessionária de energia elétrica, limitando o porte da árvore em termos de altura.

Além dos problemas com as sibipirunas, constatou-se que um grande número de árvores sofreu podas drásticas, independente de estarem ou não sob a fiação. Porém, grande parte destas podas foi ocasionada pela alta porcentagem $(60,51 \%)$ de indivíduos abaixo da rede secundária (Tabela 2).

\section{Análise da qualidade}

Nas áreas estudadas, 79,12\% dos indivíduos apresentaram bifurcação acima de 2,10 m e/ou possuíam conformação ereta, não interferindo no trânsito de veículos e/ou pedestres. Com altura de bifurcação menor que 2,10 m encontraram-se uma percentagem de $20,88 \%$ dos indivíduos (Tabela 2).

Uma espécie com percentagem elevada de indivíduos atrapalhando o trânsito de pedestres e veículos foi o Ficus benjamina, com um valor de $24,4 \%$. Apesar de ser uma espécie de grande porte e ter um sistema radicular muito agressivo, ela foi a terceira espécie mais encontrada nas duas regiões estudadas. Verificaram-se sete indivíduos plantados em uma calçada estreita junto à parede lateral da Igreja do Pilar (tombada pelo Patrimônio Histórico), que poderão ocasionar problemas futuros. 
Arborização viável na cidade de Taubaté...

Em relação à análise da condição da copa das espécies, a maioria dos indivíduos $(55,10 \%)$ da região central apresentou copa ruim (Tabela 2$)$, com aspecto atípico, e/ou com formato descaracterizado, ao contrário do bairro residencial, onde apenas 20,32\% apresentaram esta característica. Este fato é conseqüência da região central ser uma área comercial, com calçadas e vias estreitas, onde podas drásticas são verificadas, comprometendo a forma típica das espécies.

Quanto à situação das raízes, em relação ao calçamento, 66,89\% dos indivíduos apresentaram raízes subterrâneas, que não estavam danificando as calçadas, 14,68\% possuíam raízes ainda não evidentes, mas já começando a danificar o calçamento e 18,43\% possuíam raízes que estavam prejudicando severamente o calçamento (Tabela 2). A região central foi a que apresentou maiores índices de indivíduos danificando severamente as calçadas como apresentado na Tabela 2.

O sistema radicular torna-se um dos principais fatores utilizados para o critério de escolha das espécies na composição da arborização de ruas. Ele deve ser profundo de modo a não causar danos ao calçamento. Nas duas regiões analisadas, não chegam a ser alarmantes os valores encontrados referentes às raízes, porém muitas plantas eram indivíduos jovens que não atingiram seu tamanho máximo e não possuíam seu sistema radicular totalmente desenvolvido. Portanto, a característica do sistema radicular de cada espécie quando adulta é fator de extrema importância em um plantio de árvores em ruas e avenidas.

\section{Variáveis de plantio}

Na região central, grande número de árvores plantadas é de espécies inadequadas para o local $(47,22 \%)$ (Tabela 2$)$. Isso se deve a diversos fatores tais como: presença de fiação elétrica aérea, calçadas estreitas e afastamento predial inexistente. Espécies aí encontradas, tais como, sibipirunas, ficus e grevilhas, tornaram-se problemáticas para 0 local devido às suas características morfológicas.

Segundo alguns autores, deve-se considerar o tipo de rua a ser arborizada, pois vias comerciais, residenciais, entre outras, terão um tratamento distinto. Em seguida avaliar o espaço disponível, para selecionar o porte ideal da espécie a ser utilizada, que nesse caso, principalmente no centro de Taubaté, recomendam-se espécies apenas de pequeno porte (PEDROSA, 1983; PALERMO JUNIOR, 1985; CODI, 1990; RIBEIRO et al., 1992; ELETROPAULO, 1995; MILANO e DALCIN, 2000; ).

Atualmente nota-se que está havendo certo critério no planejamento deste aspecto, já que o resedá, espécie de pequeno porte, própria para locais menos espaçosos, está sendo plantado ao longo dos passeios da região central. . Assim, deve-se desejar também que seja observada a diversificação no plantio de espécies de pequeno porte (p.ex. manacá, 
pata-de-vaca, quaresmeira, ipê de jardim, murta, espirradeira entre outras) a fim de evitar os problemas gerados pela homogeneidade.

No Jardim das Nações, que é um bairro planejado, há o afastamento predial e suas calçadas são largas, o que justifica os $47,61 \%$ de espécies adequadas ao local de plantio. No entanto, é o plantio sob a fiação elétrica que contribui para que um valor total de $52,39 \%$ de espécies esteja parcialmente adequado ou inadequado ao local.

Em relação à área livre junto ao tronco (Tabela 2), de todos os indivíduos levantados, $50,85 \%$ apresentaram área livre boa, ampla ou suficiente para receber irrigação e realização de trocas gasosas. Segundo Auer (1996), a atividade microbiana do solo e o arejamento do sistema radicular das árvores plantadas são prejudicados pela cobertura de concreto e asfalto e estes indivíduos entram em declínio, expresso visualmente pelo amarelecimento da folhagem, crescimento retardado e ressecamento de galhos e ponteiros.

Quanto à rede elétrica aérea, foi constatado que pouco menos da metade das plantas (43,13\%) estava sob fiação e $56,87 \%$ dos indivíduos não estavam plantados sob a rede. Valores próximos a este foram encontrados por Milano (1984) em Curitiba - PR (53,54\%); por Lima (1993) em Piracicaba - SP (55,92\%) e por Rachid (1999) em São Carlos - SP $(47,83 \%)$.

Atualmente, mesmo com as muitas recomendações técnicas referentes à coexistência da arborização e da rede elétrica, verifica-se que muitas espécies tais como fícus, tuia e chapéu-de-sol, cuja poda causa descaracterização arquitetônica da copa e cujo porte é inadequado para o plantio sob a fiação, continuam sendo plantadas. É de extrema importância que a escolha da espécie seja de porte e forma de copa compatível com a altura da fiação. O uso de espécies de pequeno porte sob a rede pode minimizar ou tornar inexistente a poda, bem como reduzir os índices de desligamentos da rede elétrica. Destaca-se que também é possível o emprego de espécies de grande porte desde que o modelo arquitetural da sua copa permita proceder poda de condução sem descaracterização de sua forma original

Foram diagnosticados problemas relativos à poda em $62,17 \%$ das plantas na região central. Esta situação é ainda mais grave quando se constata que quase a metade das árvores levantadas $(49,05 \%)$ sofreu podas drásticas, deixando os espécimes descaracterizados e comprometendo os indivíduos. Nesta região, 80\% das sibipirunas sofreram este tipo de tratamento, confirmando que espécies de porte inadequado aos locais de plantio são as que mais sofreram intervenções quase sempre sem critérios técnicos. Os valores encontrados são motivos de preocupação já que, pelo que se constatou na arborização de Taubaté, podas drásticas, executadas sem critérios técnicos e sem equipes capacitadas, estão sendo realizadas por toda a cidade. A alta porcentagem de árvores não interferindo na iluminação $(89,90 \%)$ deve-se, dentre outros fatores, às podas realizadas 
Arborização viável na cidade de Taubaté...

quase sempre de forma drástica. Além disso, foram encontrados seis indivíduos descaracterizados, todos no Jardim das Nações, sendo quatro de tamboril, um de pata-devaca e um de ipê-roxo, provavelmente por podas malfeitas e atos de vandalismo.

TABELA 2: Porcentagens de indivíduos arbóreos relacionados aos atributos analisados em duas áreas do município de Taubaté-SP.

\begin{tabular}{|c|c|c|c|c|c|c|c|c|c|c|}
\hline & \multicolumn{3}{|c|}{$\begin{array}{l}\text { Altura da árvore em relação à rede } \\
\text { elétrica: } \\
\text { (1) abaixo; } \\
\text { (2) entre a primária e secundária; } \\
\text { (3) acima da rede primária }\end{array}$} & \multicolumn{3}{|c|}{$\begin{array}{c}\text { PAP }(\mathrm{m}) \\
\text { Perímetro da circunferência à } \\
\text { altura do peito }\end{array}$} & \multicolumn{4}{|c|}{$\begin{array}{l}\text { Condições da raiz em relação ao } \\
\text { calçamento: } \\
\text { (1) superficial causando danos; } \\
\text { (2) pouco superficial; } \\
\text { (3) sem danos }\end{array}$} \\
\hline legendas & 1 & 2 & 3 & máxima & mínima & média & 1 & 2 & & 3 \\
\hline Centro & 46,48 & 21,13 & 32,39 & 2,10 & 0,40 & 1,12 & 28,17 & 15 & & 56,34 \\
\hline $\begin{array}{c}\text { Jd. } \\
\text { Nações }\end{array}$ & 64,60 & 17,70 & 17,70 & 2,55 & 0,10 & 0,94 & 15,32 & 14 & & 70,27 \\
\hline \multirow[t]{2}{*}{ Geral } & 60,51 & 18,47 & 21,02 & 2,55 & 0,10 & 0,98 & 18,43 & 14 & & 66,89 \\
\hline & \multicolumn{3}{|c|}{$\begin{array}{l}\text { Bifurcação em relação ao trânsito } \\
\text { de veículos e/ ou pedestres: } \\
\text { (1) interferindo; } \\
\text { (2) sem interferência }\end{array}$} & \multicolumn{3}{|c|}{$\begin{array}{l}\text { Condição de copa: } \\
\text { (1) ruim; } \\
\text { (2) razoável; } \\
\text { (3) boa }\end{array}$} & \multicolumn{4}{|c|}{$\begin{array}{l}\text { Fiação sobre a árvore analisada: } \\
\text { (1) rede primária; } \\
\text { (2) rede secundária; } \\
\text { (3) primária e secundária; } \\
\text { (4) inexistente }\end{array}$} \\
\hline legendas & \multicolumn{2}{|l|}{1} & 2 & 1 & 2 & 3 & 1 & 2 & 3 & 4 \\
\hline Centro & \multicolumn{2}{|c|}{17,00} & 3,00 & 55,10 & 20,41 & 24,49 & 12,50 & 16,67 & 15,28 & 55,55 \\
\hline $\begin{array}{c}\text { Jd. } \\
\text { Nações }\end{array}$ & \multicolumn{2}{|c|}{21,82} & 8,18 & 20,32 & 9,09 & 70,59 & 1,46 & 18,66 & 22,74 & 57,14 \\
\hline \multirow[t]{2}{*}{ Geral } & \multicolumn{3}{|c|}{20,88} & 27,54 & 11,44 & 61,02 & 3,37 & 18,31 & 21,45 & 56,87 \\
\hline & \multicolumn{3}{|c|}{$\begin{array}{l}\text { Porte da espécie: } \\
\text { (1) totalmente inadequada; } \\
\text { (2) razoavelmente adequada; } \\
\text { (3) adequada ao espaço físico }\end{array}$} & \multicolumn{3}{|c|}{$\begin{array}{l}\text { Área livre junto ao tronco: } \\
\text { (1) inexistente; } \\
\text { (2) pequena área livre; } \\
\text { (3) área livre boa }\end{array}$} & \multicolumn{4}{|c|}{$\begin{array}{l}\text { Qualidade e classificação da poda: } \\
\text { (1) drástica; } \\
\text { (2) sem poda de condução; } \\
\text { (3) mal feita; } \\
\text { (4) adequada }\end{array}$} \\
\hline legendas & 1 & 2 & 3 & 1 & 2 & 3 & 1 & 2 & 3 & 4 \\
\hline Centro & 47,22 & 12,50 & 40,28 & 34,72 & 25,00 & 40,28 & 49,05 & 1,89 & 18,87 & 30,19 \\
\hline $\begin{array}{c}\text { Jd. } \\
\text { Nações }\end{array}$ & 22,99 & 29,40 & 47,61 & 11,37 & 35,57 & 53,06 & 20,09 & 16,35 & 23,83 & 39,73 \\
\hline Geral & 27,27 & 26,29 & 46,44 & 15,42 & 33,73 & 50,85 & 25,84 & 13,48 & 22,85 & 37,83 \\
\hline
\end{tabular}

\section{CONCLUSÕES}

De acordo com os dados levantados concluiu-se que a arborização viária nas áreas estudadas do município de Taubaté-SP é problemática, principalmente no centro histórico, quanto às variáveis: condição da copa, local de plantio (porte) e poda. A partir das informações obtidas recomendam-se as seguintes medidas: 
- Em regiões de centros históricos, área com ruas e calçadas estreitas, edificações sem recuo e presença de fiação, a escolha da espécie arbórea deve ficar limitada às de pequeno porte que não interfiram no tráfego de pedestres e fachadas prediais;

- Onde a arborização coexiste com a rede elétrica ou onde se projeta o plantio de espécies arbóreas sob a fiação, recomenda-se que sejam trocados os cabos da rede de energia por cabos protegidos, como já vem sendo feito em inúmeras cidades brasileiras. Isto abre a possibilidade de se empregar espécies ao menos de médio porte, aumentando-se a diversidade da arborização do local. Apesar de gerar custos, a tecnologia existe e seu uso deve ser incentivado, pois trará vários benefícios não só à arborização como às pessoas;

- As podas, bem como todo o manejo, devem ser realizadas por equipes qualificadas e treinadas, principalmente quando há conflito com a rede elétrica, de forma a garantir uma convivência harmoniosa entre as árvores e a rede de distribuição de energia.

Para a obtenção dos benefícios da arborização, torna-se necessário um planejamento prévio e para a arborização já implantada, um sistema de monitoramento que permita avaliar as características das árvores e seus respectivos locais de plantio. Essas informações irão embasar a gestão e o manejo da arborização urbana e irão definir normas, planos e projetos adequados e eficientes para cada situação urbana.

\section{REFERÊNCIAS BIBLIOGRÁFICAS}

ANGELIS NETO, G.; ANGELIS, B.L.D.; DALL'AGNOL, I.C.S.; KRELING, W.L. O controle de processos em áreas urbanas com o uso da vegetação. Revista da Sociedade Brasileira de Arborização Urbana, Piracicaba, v.1, n.1, 2006.

AUER, C.G. Doenças de árvores urbanas. Colombo: EMBRAPA - CNPF, 1996. 18p. (EMBRAPA - CNPF. Documentos, 28).

BORTOLETO, S.; SILVA FILHO, D.F.; LIMA, A.M.L.P. Prioridades de manejo para a arborização viária da estância de Águas de São Pedro-SP, por Setores. Revista da Sociedade Brasileira de Arborização Urbana, Piracicaba, v.1, n.1, p.62-73, 2006.

CODI - COMITÊ DE DISTRIBUIÇÃO. Diretrizes e critérios para harmonização de redes aéreas de distribuição e a arborização. Documento Técnico CODI - 16.11. Rio de Janeiro, 1990. p. irreg.

CRISPIM, A. A. Arborização Urbana em Volta Redonda - RJ - Levantamento nos bairros Paulo de Frontin e Vila Santa Cecília. Volta Redonda, 2000. 138 f. Dissertação 
Arborização viável na cidade de Taubaté...

(Mestrado em Ciências Ambientais e Florestais) - Universidade Federal Rural do Rio de Janeiro.

ELETROPAULO - SP. Eletricidade de São Paulo S.A. Arborização Urbana. Disponível em: <http://www.eletropaulo.com.br/portal/institucional.cfm?action=detail\&tipoinst=meio\&conteud o_id=466\&desc=Arboriza\%E7\%E3o\%20Urbana > Acesso em: 16 de dezembro 2008.

ELETROPAULO METROPOLITANA - ELETRICIDADE DE SÃO PAULO S.A.I PREFEITURA DO MUNICÍPIO DE SÃO PAULO. Guia de arborização urbana. São Paulo, s.d. $71 p$.

GOYA, C.R. Os jardins e a vegetação do espaço urbano: um patrimônio cultural. In: II CONGRESSO BRASILEIRO DE ARBORIZAÇÃO URBANA; V ENCONTRO NACIONAL SOBRE ARBORIZAÇÃO URBANA. Anais... São Luiz: SBAU, p. 133-145, 1994.

LIMA, A.M.L.P. Piracicaba/SP: Análise da arborização viária na área central e em seu entorno. Tese (Doutorado em Solos e Nutrição de Plantas) - Escola Superior de Agricultura "Luiz de Queiroz", Universidade de São Paulo. Piracicaba, 238 f. 1993.

LORENZI, H. Árvores brasileiras: manual de identificação e cultivo de plantas arbóreas nativas do Brasil. Nova Odessa: Plantarum, 1998. 352 p.

LORENZI, H., SOUZA, H.M. DE; TORRES, M.A.V.; BACHER, L.B. Árvores exóticas no Brasil: Madeireiras, ornamentais e aromáticas. Nova Odessa: Instituto Plantarum, 368 p. 2003.

MILANO, M.S. Avaliação e análise da arborização de ruas de Curitiba - PR. Dissertação (Mestrado em Engenharia Florestal) - Universidade Federal do Paraná. Curitiba, 130 f. 1984.

MILANO, MS; DALCIN, E. Arborização de vias públicas. Rio de Janeiro: Light, 206 p. 2000

OLIVEIRA JUNIOR, A.V.C. Redução dos custos operacionais de empresas de distribuição de energia elétrica através da adequação da arborização urbana. Curso em treinamento sobre poda em espécies arbóreas florestais e de arborização urbana. IPEF - Instituto de Pesquisas e Estudos Florestais, Universidade de São Paulo, 1996. 6 p.

PALERMO JUNIOR, A. Arborização, 2.ed. In: Coleção Ecossistemas Terrestres, 005. São Paulo, CESP,1985. 64p.

PEDROSA, J.B. Arborização de cidades e rodovias. Belo Horizonte: Instituto Estadual de Florestas, 1983. 64 p. 
RACHID, C. Estudo da eficiência de dois métodos de amostragem de árvores de rua na cidade de São Carlos - SP. Dissertação (Mestrado em Recursos Florestais - Escola Superior de Agricultura "Luiz de Queiroz", Universidade de São Paulo. Piracicaba, 99 f. 1999.

RiBeiRo, M. A.; CAStRo, C. A. de; ReIS, E. M. B. G.; TAVARES, M.; BAgGiO, P. Programa de arborização de Belo Horizonte - Projeto Verde Vivo. In: ENCONTRO NACIONAL SOBRE ARBORIZAÇÃO URBANA, 4. , Vitória, 1992. Anais... Vitória, Prefeitura Municipal de Vitória, 1992. v.1, p.161 - 74.

SANCHOTENE, M.C. Frutíferas Nativas Úteis à Fauna na Arborização Urbana. Porto Alegre: Editora FEPLAN, 311 p. 1985.

SÃO PAULO (cidade). Manual Técnico de Poda de Árvores. Secretaria Municipal do Verde e do Meio Ambiente, p.16-22, 2006.

SEITZ, R. A. Considerações sobre a poda de árvores na arborização urbana. In: ENCONTRO NACIONAL SOBRE ARBORIZAÇÃO URBANA, 3. , Curitiba, 1990. Anais... Curitiba: FUPEF. p. 87-100.

SILVA, A.G.; GONÇALVES, W.; LEITE, H.G.; SANTOS, E. Comparação de três métodos de obtenção de dados para avaliação quali-quantitativa da arborização viária, em Belo Horizonte-MG.

TOLEDO FILHO, D.V.; PARENTE, P.R. Arborização urbana com essências nativas. Boletim Técnico do Instituto Florestal, São Paulo, v. 42, p.19-31, 1988.

YAMAMOTO, M.A.; SCHIMIDT, R.O.L.;COUTO, H.T.Z.; SILVA FILHO, D.F. Árvores Urbanas. $\quad$ Piracicaba. $2004 . \quad$ Disponível http://lmq.esalq.usp.br/ dfsilva/arvores urbanas.pdf Acessado em: 21/11/2007. 